\title{
Chilling injury in pineapple fruits: physical quality attributes and antioxidant enzyme activity
}

\author{
1,*Dolhaji, N.H., ${ }^{2}$ Muhammad, I.D., ${ }^{2,3}$ Yaakob, H. and ${ }^{2}$ Mohd Marsin, A. \\ ${ }^{I}$ Faculty of Plantation and Agrotechnology, Universiti Teknologi MARA (UiTM) Jasin. Melaka, Malaysia \\ ${ }^{2}$ School of Chemical and Energy Engineering, Faculty of Engineering, Universiti Teknologi Malaysia \\ (UTM) Skudai. Johor. Malaysia \\ ${ }^{3}$ Institute of Bioproduct Development, Universiti Teknologi Malaysia (UTM) Skudai, Johor, Malaysia
}

\author{
Article history: \\ Received: 22 July 2020 \\ Received in revised form: 3 \\ December 2020 \\ Accepted: 14 December 2020 \\ Available Online:
}

\section{Keywords:}

Pineapple,

Antioxidant activity,

Antioxidant enzyme,

Chilling injury,

Physical quality attributes

\section{DOI:}

https://doi.org/10.26656/fr.2017.4(S5).004

\begin{abstract}
Harvested fruit have high metabolic and moisture content which leads to an active biochemical reaction that contributes to decrement of nutritional value such as vitamin, proteins and lipids. The application of low temperature as a single-effective management to prolong shelf-life of fruits is a common practice which applied to keep agriculture commodities at high quality. A matured stage pineapple is very perishable and cold storage chain is crucial in maintaining the chemical and physical quality attributes in order to assure its commercial value for market. The main objective of this study is to evaluate the effect of sub-optimum cold storage scenario on changes of pineapple fruits physical quality attributes, the activity of browning enzyme and antioxidant related enzyme in 2 pineapple cultivars (cv.), Morris (Queen-type) and Josapine (hybrid of Spanish and Smooth Cayeen). Malaysian pineapple fruit cv. with different sensitivity toward CI, Morris (Queen-type) and Josapine (Smooth-Cayenne-type) were stored at sub-optimal storage temperatures $\left(4 \pm 2^{\circ} \mathrm{C}\right)$ for 28 days to investigate the effects of $\mathrm{CI}$ towards physical quality attributes and antioxidant enzyme activity. The result indicated both cv. was affected with CI towards the 28 days of sub-optimum cold storage. Overall physical quality attributes indicated CI was found positively correlated with the increase of EL and TTA and on the contrary decrease its firmness, weight $(\% \mathrm{w} / \mathrm{w})$, brightness $\left(\mathrm{L}^{*}\right)$ and redness $\left(A^{*}\right)$. Similarly, a positive correlation was also deduced between CI symptoms and the activities of PPO and APX which reflect the incident of oxidative stress. The results derived from this study may serve as a basis for evaluation of better postharvest strategies to control CI during cold chain storage of pineapple fruits and thus assure the quality and nutritional value till it reaches to consumer.
\end{abstract}

\section{Introduction}

Determination of overall quality of fruits is very complex which includes the preharvest factors (growing region, genetic, soil, climatic condition and cultural practices) and also postharvest factors involving a chain starting at maturity during harvest until being put on the shelf. One important component in postharvest is cold storage in order to maintain a longer shelf life. Harvested fruits have high metabolic and moisture content which leads to an active biochemical reaction resulting to decrease in nutritional value such as vitamin, proteins and lipids (Neto et al., 2005). Currently, the application of low temperature as a single-effective control approach to prolong shelf-life of fruits is commonly applied for keeping agriculture commodities at high quality (Hong et al., 2013).

Pineapple fruit is categorised as non-climacteric where the fruit is harvested at optimum maturity for consumption (Hassan et al., 2011; Lobo and Yahia, 2016). A matured stage pineapple is very perishable where cold storage is crucial to maintain the quality attributes chemically and physically in order to meet the market standard. Pineapple is a good source of vitamins and minerals. Its high phenolic content indicates pineapple as a good source of antioxidant (Hossain and Rahman, 2011). Lin and Zhao (2007) characterised the quality of fresh fruits based on appearance, texture, flavour and nutritional value. Meanwhile, Paull and Chen (2003) determined pineapple quality according to 
its colour, size, shape, aroma, firmness and weight. Until today very few studies have been published regarding the influence of sub-optimum cold storage on the physical quality of Malaysia pineapple cultivar

Postharvest chilling injury is a state where fruits show a symptom of injury with 2 phases starting with a temperature-dependent phase which is revisable, leading to the loss of membrane integrity known as a transition state. The second stage is called the irreversible second phase where both temperature and time are dependent (Luengwilai et al., 2018). The second stage triggers a reaction with symptoms such as electrolyte leakage reduction in metabolic energy and cell lysis. As for pineapple, water soaking patches is the early sign that can be found at the flesh close to the core and these patches will further change to brown colour.

Abiotic stress including sub-optimum cold storage could trigger an accumulation of reactive oxygen species (ROS). Oxidative damage by ROS may be avoided by an effective antioxidant mechanism. Based on fact, plant tissue with a better antioxidant system would be more resistant to low temperature (Blokhina et al. 2003). Previous evidence showed that better antioxidant system and ROS generation are related in the development of chilling injury. This explains the importance of antioxidant related enzyme activities such as ascorbate peroxidase (APX) and catalase (CAT) to reduce the chilling injury. The main objective of this study was to determine the effect of sub-optimum cold storage on changes in physical quality attributes (total soluble solid, colour, texture, $\mathrm{pH}$, TTA and ion leakage), the activity of browning enzyme (PPO) and antioxidant related enzyme (APX and CAT) in two Malaysian pineapple cultivars, Morris (Queeen-type) and Josapine (hybrid of Spanish and Smooth Cayeen).

\section{Materials and methods}

\subsection{Preparation of plant material}

Morris (Queen-type) and Josapine (hybrid of Smooth Cayenne-type) pineapple fruits (Ananas comosus L.) were purchased from local planters and exporter in Pontian and Sempang Renggam, Johor. Malaysia. Pineapples were harvested at the mature-green stage of maturity (index 3), where the skin is still green with 1- 2 eyes of the fruit have turned to yellow colour, according to Federal Agricultural Marketing Authority of Malaysia (FAMA). Fruits with no physical damage and no visible disease symptoms of about $1.5-1.8 \mathrm{~kg}$ were transported at $25^{\circ} \mathrm{C}$ to the laboratory, washed, disinfected with sodium hypochlorite and were spray with 100ppm of fungicide (BENOMYL 50WP®).

\subsection{Chilling injury treatment}

The experiment was conducted in a completely randomised design (CRD), where 60 fruits of each cultivar were packed and randomly divided into 3 batches, placed into a commercial cardboard box (14 x $32 \times 49 \mathrm{~cm}$ ) for export (Zaulia and Suhaila, 2007) and stored at sub-optimal storage temperatures $\left(4 \pm 2^{\circ} \mathrm{C}\right)$ with $85 \pm 5 \%$ relative humidity (RH). Fruits were further randomly sampled and evaluated on $0,7,14,21$ and 28 days after storage (3 replications; 5 fruits per replication).

\subsection{Chilling injury score}

Chilling injury and browning symptoms were assessed visually according to the percentage of the cut area that exhibited water-soaking translucency and browning symptoms respectively, by cutting the fruit in half longitudinally, through the middle, $24 \mathrm{hrs}$ after it was transferred to room temperature (Abdullah et al., 2008). The symptoms were scored subjectively according to the percentage of flesh with water-soaking translucency and browning area with reference to the standard chart for each cultivar (Youryon et al., 2013)

\subsection{Browning evaluation by colour measurement}

Colour was measured using Konica Minolta CR-10 calorimeter. (Konica Minolta, Tokyo, Japan) according to the CIELAB colour parameter L*(lightness), $a^{*}$ (green chromaticity) and $b^{*}$ (yellow chromaticity). The calorimeter was set up as illuminant D65 at $10^{\circ}$ observer angle. Numerical values of $\mathrm{L}^{*}, \mathrm{a}^{*}, \mathrm{~b}^{*}$ and browning index (BI) were considered for the evaluation of colour modification of fresh-cut pineapples. The browning index was calculated according to the method described by (Youryon et al., 2018) Browning index is an indicator of the intensity of brown discoloration and calculated as follow:

$$
B I=\frac{100(x-0.31)}{0.172}
$$

Where

$$
x=\frac{a *+1.75 L *}{(5.646 L *+a *)-(3.012 b *)}
$$

\subsection{Firmness}

Texture analysis of the pineapple flesh was measured using texture analyser (Brookfield CT3, Middleboro, MA, USA) with a TA11/1000 cylinder probe at a speed of $0.5 \mathrm{~mm} / \mathrm{s}$. Firmness was recorded as a maximum load pressure in Newtons $(\mathrm{N})$ applied to the pineapple with size $30 \mathrm{~mm} \times 30 \mathrm{~mm}$ pulp to compress $50 \%$ of its initial height. 


\subsection{Soluble solid concentration, $\mathrm{pH}$ and titratable acid}

Total soluble solids concentration (TSS) in the samples was measured using a digital hand-held refractometer (Bellingham Stanley) and expressed in ${ }^{\circ}$ Brix scale (AOAC, 2000). $\mathrm{pH}$ of the filtered extract was measured using a benchtop $\mathrm{pH}$ meter (Orion 2 Star ${ }^{\circledR}$ ). The working temperature for the measurements is $25^{\circ} \mathrm{C}$. The average value of three replications (5 fruit each replicate) was reported

\subsection{Weight loss}

The weight of pineapple fruit was measured before the suboptimum storage (initial weight) and after storage at an interval of 7 days (final weight) up to 28 days. The percentage of weight loss is calculated as follow:

$$
\% \text { weight loss }=\frac{\text { initial weight }- \text { final weight }}{\text { initial weight }} \times 10 \mathrm{C}
$$

\subsection{Electrolyte leakage}

Ion leakage (EL) of the fruit flesh was analysed as per the method described by (Nukuntornprakit et al., 2015). Fresh pulp sample $(3.0 \mathrm{~g})$ was cut into pieces of about $0.5 \mathrm{~cm} \times 0.5 \mathrm{~cm} \times 0.5 \mathrm{~cm}$. The dices were washed and decanted for 3 times with distilled water. The dices were then be added with $50 \mathrm{~mL}$ of $0.4 \mathrm{M}$ mannitol solution. Then, the sample was shaken at $100 \mathrm{rev} / \mathrm{min}$ on a rotary shaker for $1 \mathrm{hr}$. The conductivity was measured using a conductivity meter as E1. The samples were then autoclaved at $121^{\circ} \mathrm{C}$ for 30 mins and left to cool to $25^{\circ} \mathrm{C}$. The conductivity was re-measured as E2. Actual EL is expressed in percentage by dividing the difference between the values before autoclave (E1) and after autoclave (E2) with conductivity reading after the sample had been autoclaved (E2).

\subsection{Enzyme extraction}

The extraction of polyphenol oxidase (PPO) crude enzymatic solution was done by referring to the technique by Zhang and Shao (2015). A $20 \mathrm{~g}$ of fruit flesh were homogenised with $100 \mathrm{~mL}$ of $0.1 \mathrm{M}$ sodium phosphate buffer $(\mathrm{pH} \quad 6.5)$ containing $1 \%$ polyvinylpolypyrrolidone. The mixture was centrifuged at $9540 \mathrm{rpm}$ at $4^{\circ} \mathrm{C}$ for 10 mins and the supernatant was collected for PPO enzyme assay. As for ascorbate peroxidase (APX), superoxide dismutase (SOD), peroxidase (POD) and catalase (CAT) enzyme assays, 3 $\mathrm{g}$ of frozen tissues sample were homogenized at $4^{\circ} \mathrm{C}$ in 7 $\mathrm{mL}$ of $100 \mathrm{mM}$ potassium phosphate buffer complex $(\mathrm{pH}$ 7.0), containing $1.0 \mathrm{mM}$ ethylenediaminetetraacetic acid (EDTA), $5 \%(\mathrm{w} / \mathrm{v})$ polyvinylpolypyrrolidone and $1 \%(\mathrm{v} /$ v) Triton $X-100$. The homogenate was centrifuged at $13,000 \times g$ at $4^{\circ} \mathrm{C}$ for 20 mins. The supernatant was collected and used for the above-mentioned enzyme assays.

\subsection{Polyphenol oxidase activity}

PPO activity was quantified as per the method described by (Zhang and Shao, 2015). The reaction reagent contained a mixture of $1.5 \mathrm{~mL}$ of $40 \mathrm{mmol} / \mathrm{L}$ catechol with $2.3 \mathrm{~mL}$ of $0.1 \mathrm{~mol} / \mathrm{L}$ phosphate buffer $(\mathrm{pH}$ 6.5). Reaction reagent was incubated in $25^{\circ} \mathrm{C}$ water bath for 5 mins. Then, $0.2 \mathrm{~mL}$ of the crude enzyme was added to the reaction reagent test tube and mixed thoroughly. Immediately, the reaction mixture was measured at 420 nm UV-VIS Jenway 7305 spectrophotometer, and the result was recorded at every $30 \mathrm{~s}$ interval for 3 mins. The activity is expressed as one enzymatic unit (U) equivalent to $0.001 \Delta \mathrm{A} 420 / \mathrm{min} / \mathrm{g}$ of fresh weight.

\subsection{Ascorbate peroxidase activity}

Catalase (CAT) activity was tested by monitoring the decrement in absorbance at $240 \mathrm{~nm}$ for $10 \mathrm{~min}$ at $25^{\circ} \mathrm{C}$, where the reaction mixture was consists of $3.0 \mathrm{~mL}$ of 5 $\mathrm{mM} \mathrm{H}_{2} \mathrm{O}_{2}$ in $50 \mathrm{mM}$ potassium phosphate buffer $(\mathrm{pH}$ 7.0) and $0.1 \mathrm{~mL}$ of the enzyme extract. Every unit of enzyme activity is equivalent to the amount that triggered a change of 0.01 in absorbance per minute. The specific CAT activity was expressed as one enzymatic unit, (U) equivalent to $0.01 \Delta \mathrm{A} 240 / \mathrm{min} / \mathrm{g}$ fresh weight

\subsection{Catalase activity}

Catalase (CAT) activity was tested by monitoring the decrement in absorbance at $240 \mathrm{~nm}$ for 10 mins at $25^{\circ} \mathrm{C}$, where the reaction mixture consists of $3.0 \mathrm{~mL}$ of $5 \mathrm{mM}$ $\mathrm{H}_{2} \mathrm{O}_{2}$ in $50 \mathrm{mM}$ potassium phosphate buffer $(\mathrm{pH} \mathrm{7.0)}$ and $0.1 \mathrm{~mL}$ of the enzyme extract. Every unit of enzyme activity is equivalent to the amount that triggered a change of 0.01 in absorbance per minute. The specific CAT activity was is expressed as one enzymatic unit, (U) equivalent to $0.01 \Delta \mathrm{A} 240 / \mathrm{min} / \mathrm{g}$ fresh weight

\subsection{Statistical analysis}

For this research work, one-way ANOVA and independent paired t-test data analysis were performed using SPSS Inc. software (20th version). A significant level of $p<0.05$ was used to determine the main and interaction effects among the factors studied.

\section{Results}

\subsection{Chilling Injury (CI) and Internal Browning (IB)}

The chilling injury symptoms at day 7 of cold storage were observed at the flesh pulp which showed discoloration and tissues became translucent as the water soaking area formed a water patch which indicates of cell death (Figure 1). This is followed by changes in the 
CI impacted areas to brown which indicates internal browning (IB). The condition then spread and increased tremendously after 21 days of storage. There was a significant difference $(p<0.05)$ in the CI and IB development observed between cv. Josapine and Morris on day 21 (Table 1). In order to understand the effect of $\mathrm{CI}$ and IB for all samples, the monitoring was extended up to 28 days. The CI and IB effect for Josapine cv was found to increase from $3.33 \pm 2.88$ to $26.33 \pm 0.75$ of the score symptom (\%) showing of about 8 folds increment at day 28 as compared to cv. Morris with 3 folds from $9.66 \pm 2.62$ to $27.67 \pm 2.57$. However, based on the results of day 28, the effect of CI and IB between Josapine and Morris was statistically insignificant.

a)

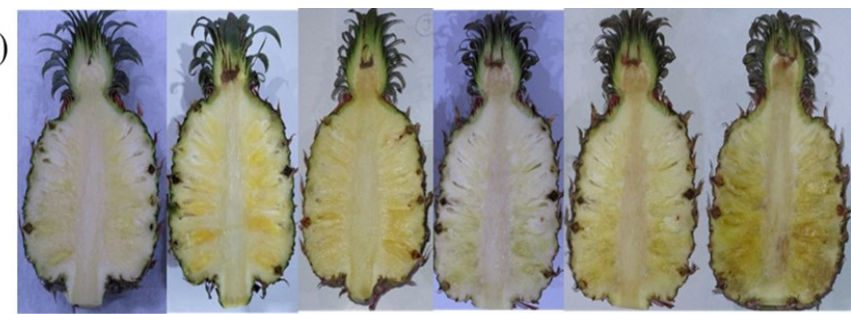

b)

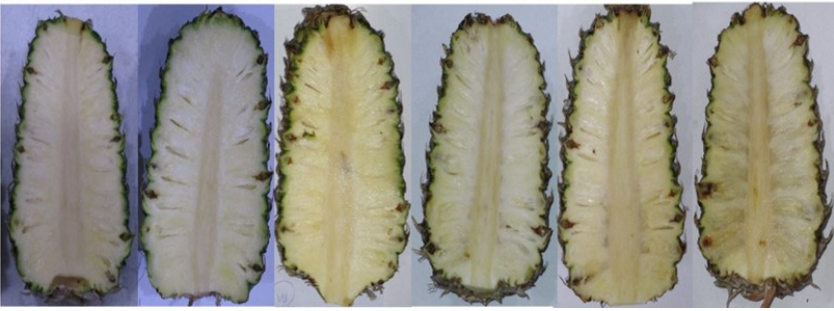

Figure 1. Weekly development of CI from day 0 to 28 (left to right) in (a) Josapine (above), (b) Morris (below) cv. pineapple during storage at $4 \pm 2^{\circ} \mathrm{C}$.

\subsection{Browning index, colour and firmness}

The appearance of food products is of major importance to consumers with regard to both acceptability and preference. The colour of the fruit is generally accepted as one of the most relevant quality parameters. Therefore, colour plays a decisive role in evaluating the quality of the fruit product at the point of sale. In this work, the effects of sub-optimal temperatures storage and CI development on the colour of the skin and pulp of pineapple fruits were investigated by studying the changes in the $\mathrm{L}^{*}, \mathrm{a}^{*}$ and browning index $(\%)$

At harvest, Josapine cv. showed no significant difference in redness $\left(a^{*}\right)$ and lightness $\left(\mathrm{L}^{*}\right)$ compared to
Morris cv. (Figure 2a and 2b). Josapine reached its maximum redness on day 14 of storage with $70.7 \%$ higher than Morris, while it decreases as storage prolonged to day 28 at $20.7 \%$. The lightness ( $\mathrm{L}^{*}$ ) exhibits a declining trend in both Josapine and Morris pineapples as they were kept longer and no differences $(p<0.05)$ were found at harvest until day 28. The browning index (\%) plotted starting at day 7 of storage and both show a continuous browning sign as they were kept longer especially as they reached day 14 of storage with 2.5 folds higher for Josapine cv. than Morris (Figure 2c).

The firmness of Josapine and Morris cv. at harvest were similar at around 59-64 $\mathrm{N}$ for $50 \%$ compression of the initial height of pineapple fruits samples. The firmness of Morris (Figure 2d) was steadily declining in a fast manner than Josapine throughout the storage with a total decrease of $57.2 \%$ and $41.2 \%$ respectively at day 28. The significant difference was found at day 14 and 21 of storage for both samples.

\subsection{TSS content, $p H$ and titratable acid}

The TSS content increased slowly up to 7 days and thereafter declined slowly in both pineapples cv. TSS is often used as indicators of fruit quality and maturity level. According to D'Eeckenbrugge and Leal (2003), a minimum of $12 \%$ Brix is required for customer acceptance of pineapple fruits. Morris cv. stored at suboptimal temperature showed lower content of TSS with significant difference $(\mathrm{p}<0.05)$ at day 7,14 and 28 compared to Josapine. The trend illustrates the increase and decrease of TSS as steady and they reached the highest TSS level between day 7 to day 14 before declining after 14 days of storage (Figure $3 a$ ). Figure $3 \mathrm{c}$ exhibits a decline in acidity for both Josapine and Morris after 7 days of storage. Josapine, in comparison, is slightly more acidic than Morris.

Titratable acid (TA) represents the concentration of organic acids present in the fruit samples and expressed as percent citric acid in the present study. A fluctuate pattern of TA was found for Josapine with an initial value of $0.65 \%$ and then gradually decrease until day 14 before increasing to $0.88 \%$ at day 21 and increase slightly to $0.99 \%$ at day 28 of storage. On contrary, a

Table 1. Chilling injury (CI) and internal browning (IB) score symptoms (\%) in 2 cultivars pineapple (Annanas comosus cv. 'Josapine' and 'Morris' (stored at $4 \pm 2^{\circ} \mathrm{C}$ from 0 to 28 days).

\begin{tabular}{lccccc}
\hline \multirow{2}{*}{ Cultivars } & \multicolumn{5}{c}{ CI, IB Score (\%) } \\
\cline { 2 - 6 } & Day 0 & Day 7 & Day 14 & Day 21 & Day 28 \\
\hline Josapine & $0.00 \pm 0.00^{\mathrm{a}}$ & $0.67 \pm 1.07^{\mathrm{a}}$ & $1.33 \pm 1.08^{\mathrm{a}}$ & $3.33 \pm 2.88^{\mathrm{a}}$ & $26.33 \pm 0.75^{\mathrm{a}}$ \\
Morris & $0.00 \pm 0.00^{\mathrm{a}}$ & $1.33 \pm 1.96^{\mathrm{a}}$ & $2.66 \pm 1.98^{\mathrm{a}}$ & $9.66 \pm 2.62^{\mathrm{b}}$ & $27.67 \pm 2.57^{\mathrm{a}}$ \\
\hline
\end{tabular}

Values are expressed as mean $\pm \mathrm{SD}$ of 3 replications. Values with different superscript within row are significantly different $(\mathrm{p}<$ $0.05)$. 

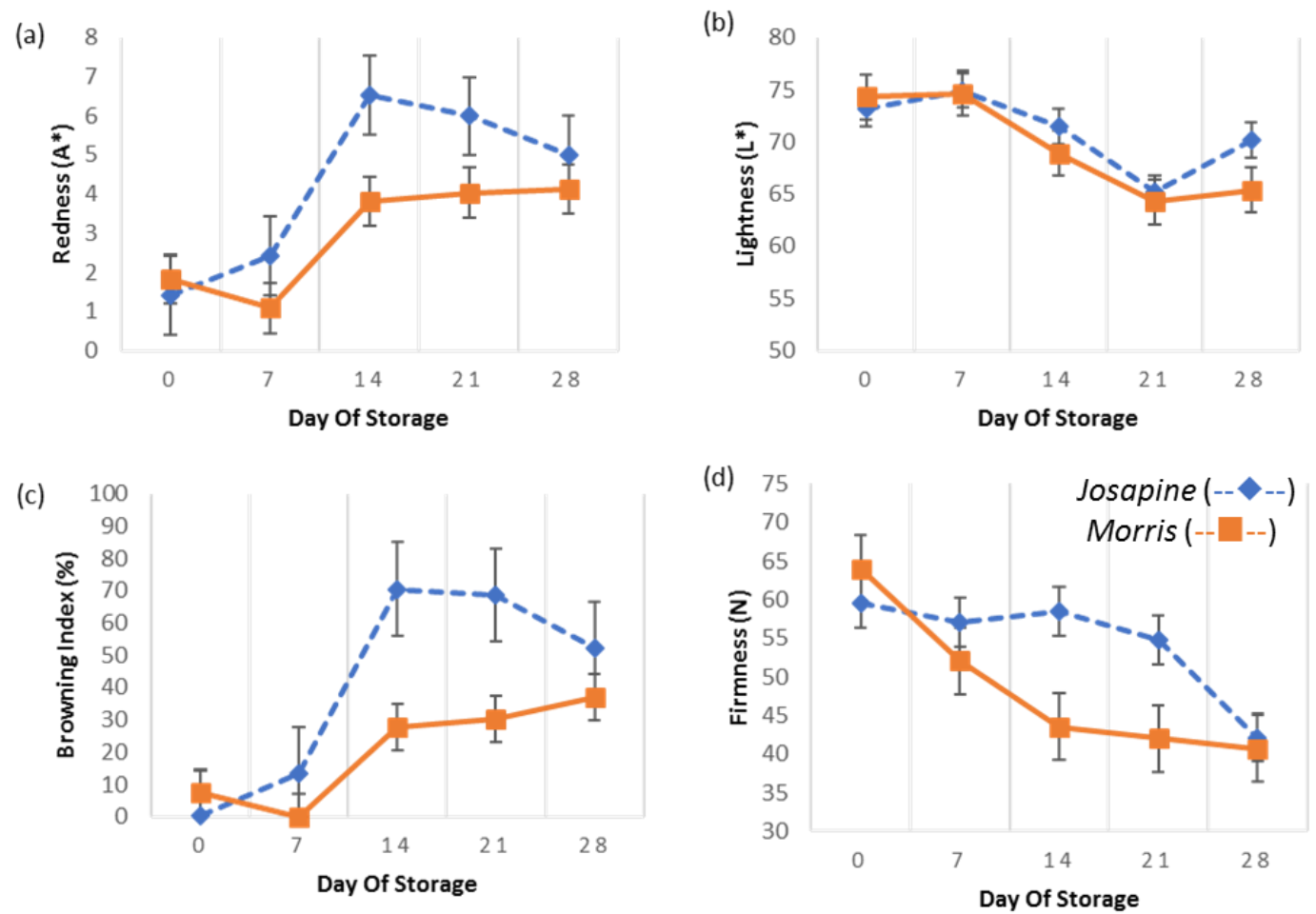

Figure 2. Redness, $\mathrm{a}^{*}(\mathrm{a})$, Lightness, $\mathrm{L}^{*}(\mathrm{~b})$, Browning index (\%) (c) and Firmness (N) (d) in cv. Josapine and Morris pineapples, stored at $4 \pm 2^{\circ} \mathrm{C}$ for $0,7,14,21$ and 28 day(s). Value (mean $\pm \mathrm{SE}$ ) of 3 replicates (each replicate containing 5 fruits).
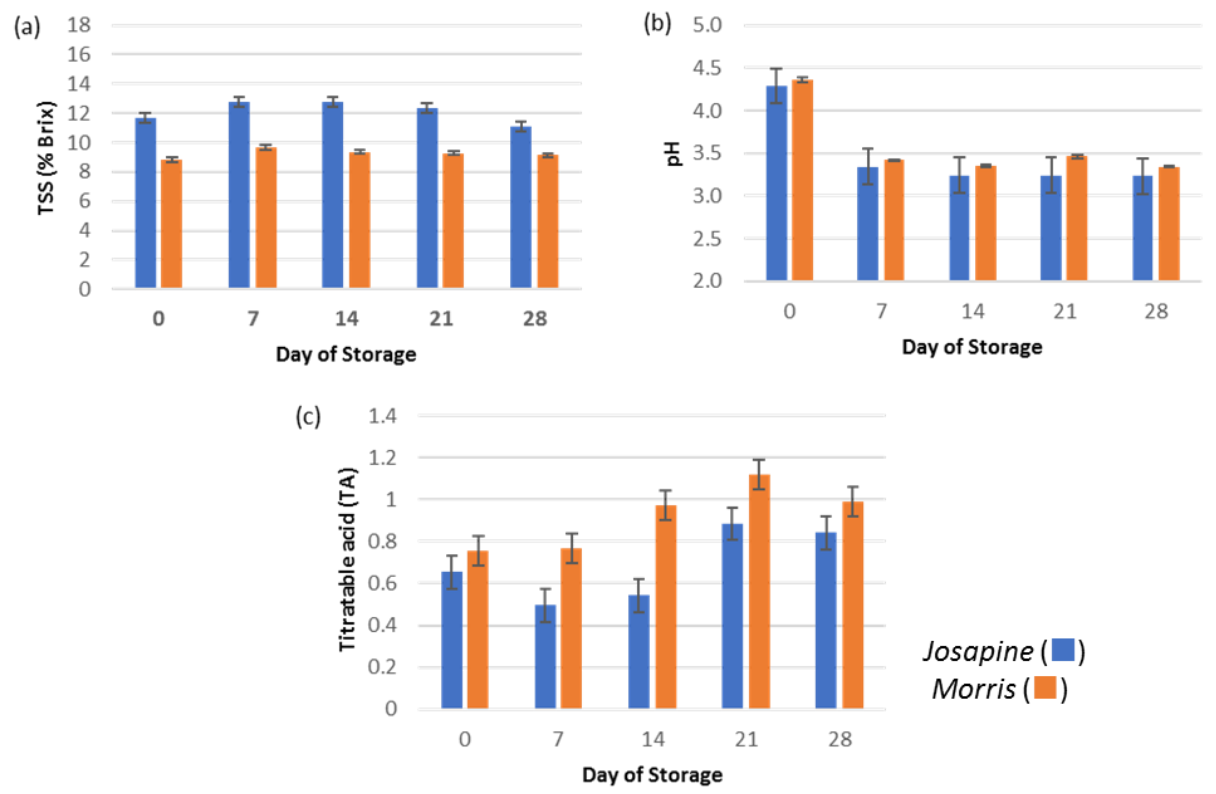

Figure 3. Total soluble sugar, TSS (a), $\mathrm{pH}$ (b) and Titratable acid (c) in cv. Josapine and Morris pineapples, stored at $4 \pm 2{ }^{\circ} \mathrm{C}$ for $0,7,14,21$ and 28 day(s). Value (mean \pm SE) of 3 replicates (each replicate containing 5 fruits).

(a)

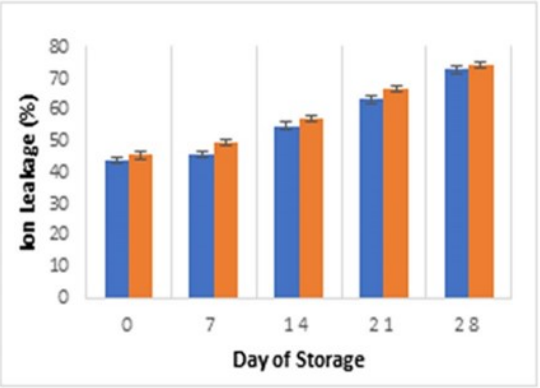

(b)

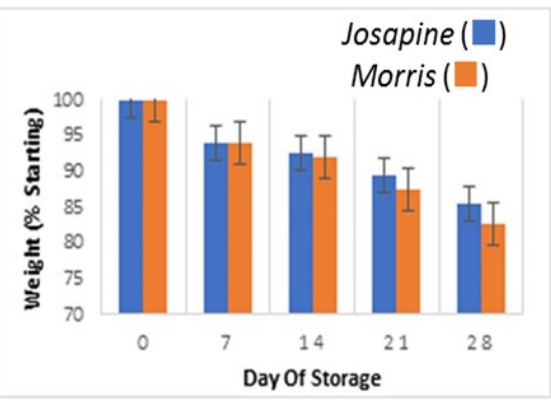

Figure 4. Weight loss (\% starting) (a) and Ion Leakage (\%) (b) and in cv. Josapine and Morris pineapples, stored at $4 \pm 2^{\circ} \mathrm{C}$ for 0 , $7,14,21$ and 28 day(s). Value (mean \pm SE) of 3 replicates (each replicate containing 5 fruits) and significant differences $(\mathrm{p}<0.05$ ) for each storage duration are indicated by different letter. 
different result was found for Morris where the TA was gradually increased at the day of storage up to day 21 with $1.1 \%$. This result showed no significant difference between both $\mathrm{cv}$.

\subsection{Weight loss and ion leakage}

As shown in Figure 4a, weight loss of both cv. was similar for the first 14 days. Meanwhile, Josapine found to have higher weight loss, compared to Morris starting on day 21 onwards. Also, after day 14 the weight loss of both was significantly different $(\mathrm{p}<0.05)$. Ion leakage (EL) determined in the pulp tissue of both cv. showed lower percentage prior to storage where Josapine with $43.78 \pm 0.95 \%$ and Morris with $45.41 \pm 0.16 \%$. In overall, there was a significant increase in EL value (Figure 4B) of both cultivars with Josapine cv. showed the highest increment in the percentage of EL.

\subsection{Polyphenol oxidase, ascorbate peroxidase and} catalase

The PPO activity of $2 \mathrm{cv}$. Pineapples are shown in Figure 5a. Josapine has higher PPO activity as compared to Morris and it reached its maximum PPO activity on day 14 but declines after longer storage. However, for Morris, the trend shows a fluctuation in PPO activity until 21 days of storage. It later declined after 21 days of storage. This fluctuation of PPO activity however showed no significant difference for both $(\mathrm{p}<0.05)$.

Ascorbate peroxidase enzyme (APX) of Josapine and Morris cv are shown in figure 5b. An increasing trend of APX activity inferring protection mechanism executed by the plants to fight reactive oxygen species in overall both samples was found to consistently increase in the amount of APX up to day 21 with Morris showed $50.1 \%$ increment while Josapine showed 45.7\% increment. However, after day 21, APX decreased to 276.4 and $268.8 \mathrm{U} / \mu \mathrm{mol} / \mathrm{gmFW}$, implying mortality.

As for catalase activity, figure $5 \mathrm{c}$ exhibits bell curve for both Josapine and Morris pineapples where the highest activity was on the $7^{\text {th }}$ day of storage where Morris are 20 folds and Josapine with 5 folds compared to the day of harvest. However, CAT activity declines significantly for both samples after 14 days of storage showing the loss in the pineapples' antioxidants to fight free radicals.

\section{Discussion}

Josapine was found to be more resistant to CI than Morris cv. at the early stage of sub-optimal cold storage but later showed no difference between both. This is support by the previous finding, which stated that Morris from Queen-type is more susceptible to CI compare to Josapine hybrids of smooth cayenne. The resistance of Smooth Cayeene hybrid however is a temporary event as the exposure time of sub-optimal was prolonged, the CI score showed no difference to the Queen-type. This finding is supported by the theory of CI phases by Luengwilai et al. (2018) where CI is a 2-stage event where it is initially temperature-dependent but becomes both temperature and time-dependent at the second stage (a)

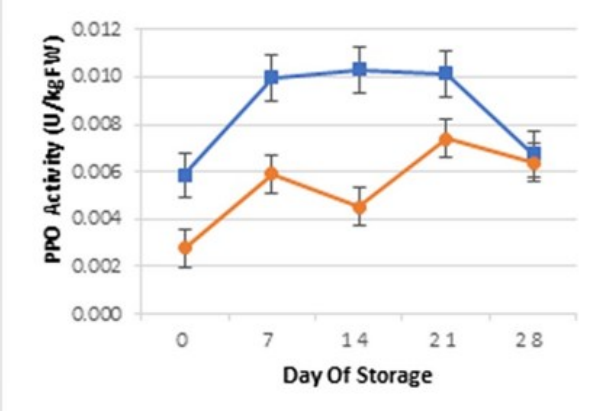

(b)

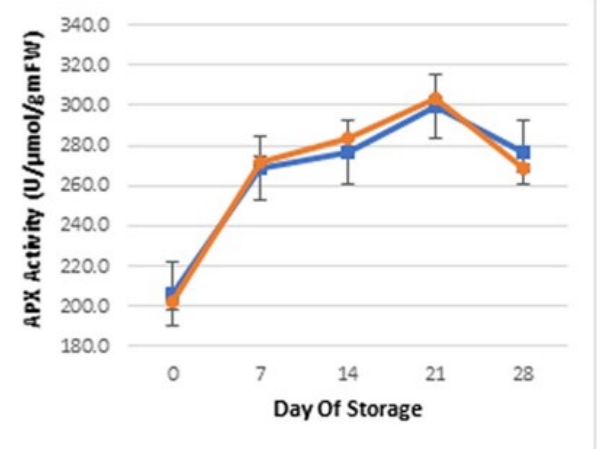

(c)

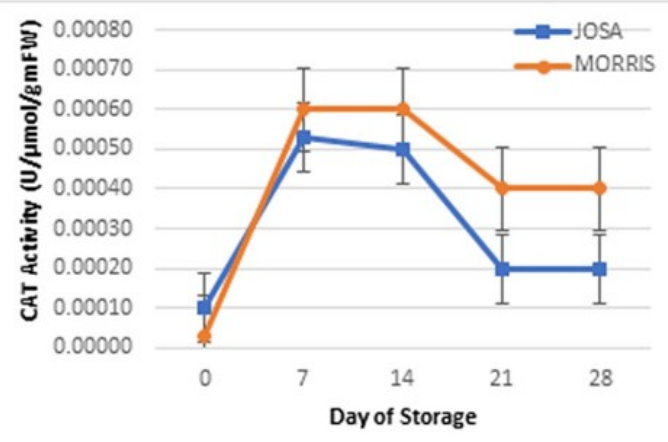

Figure 5. Polyphenol oxidase (PPO) (a), Ascorbate peroxidase (APX) (b) and Catalase (CAT) (c) in cv. Josapine and Morris pineapples, stored at $4 \pm 2^{\circ} \mathrm{C}$ for $0,7,14,21$ and 28 day(s). Value (mean \pm SE) of 3 replicates (each replicate containing 5 fruits). 
Result of both Morris and Josapine cv. pulp redness (a* value) and lightness $\left(\mathrm{L}^{*}\right)$ above demonstrate that both $\mathrm{a}^{*}$ and $\mathrm{L}^{*}$ value showed a similar trend which indicates that an increase of redness will reduce the lightness. A reduction of lightness is an indication of darkening increment (Hernández-Muňoz, et al., 2008; Youryon et al., 2018). These calorimetric changes could be explained by the increase of browning index calculated by $\mathrm{L}^{*}, \mathrm{a}^{*}$ and $\mathrm{b}^{*}$ values and $\%$ BI. In overall, Josapine shows major changes in term of colour and browning index but is similar to CI susceptible queentype cultivar, Morris.

Maintaining postharvest firmness is an important aspect to consider during fruits storage and shelf-life which determine the acceptability of horticultural commodities. It is accepted as one of the most relevant quality parameters characterising the fruit texture. Differences $(\mathrm{p} \leq 0.05)$ in firmness were observed between day 14 and 21. Morris exhibited lower firmness value throughout the storage compared to Josapine. However, at day 28 no difference was observed. According to this study, it was found that TSS (expressed in \% Brix) of Josapine is consistently high throughout storage compared to Morris. TSS is an important quality factor that attributes for many fresh fruits due to solids including the soluble sugars such as sucrose, glucose and fructose as well as acids (Tehrani et al., 2011). According to D'Eeckenbrugge and Leal (2003), a minimum of $12 \%$ Brix is required for customer acceptance of pineapple fruits as stated in the current finding Josapine cv, which meets the TSS minimum quality attributed up to 21 days of sub-optimum cold storage. According to Shamsudin et al. (2007) acceptable pineapple $\mathrm{pH}$ ranges are from 3.3 to 3.7 . As $\mathrm{pH}$ is an internal ripeness indicator (Vinson et al., 2010), $\mathrm{pH}$ plays an important role in determining the physical quality attribute of fruits. In overall, sub-optimum cold storage of Morris cv showed higher $\mathrm{pH}$ compared to Josapine with but both showed a declining pattern. The decrease in acidity is due to respiration process during storage where organic acids are used as a respiratory substrate which generates ATP (Lee et al., 2010).

Activity increment of titratable acid (expressed as \% citric acid equivalent) and reduction in acidity $(\mathrm{pH})$ represent the conversion of sugars and organic acids for further utilisation in the metabolic processes of the fruit during storage life (Ibrahim et al., 2014). According to the present study similar trend was found for both Josapine and Morris cv. where decrement in $\mathrm{pH}$ value throughout storage increased the percent value of citric acid. However significant differences $(p<0.05)$ were only found at day 14 and 21 .
Both cv. showed progressive loss of weight with storage time. Weight loss mainly occurs due to water loss by transpiration and loss of carbon reserves due to respiration (Vogler and Ernst, 1999). The rate at which water is lost depends on the water pressure gradient between the fruit tissue and the surrounding atmosphere. Excessive weight loss can lead to monetary loss due to the reduced amount of salable weight.

Ion leakage (EL) of cv. Josapine remained stable for the first 14 days of storage and with small increment by day 21 of storage. In contrast, for cv Morris showed a high percentage of ion leakage started as early as 7 days of storage. EL is the key indicator of membrane damage and loss of membrane integrity due to respiration rate (Shadmani et al., 2015) and this indicated that cv Morris showed early onset of membrane damage and sensitivity towards sub-optimal cold storage temperature compared to cv Josapine.

Polyphenol oxidase (PPO) activity for both cv. was very low upon harvested. In contrast, the activity was then dramatically double at day 14 of sub-optimal cold storage. The results were consistent with the previous report by Hong et al. (2013) and Zhou et al. (2003) where PPO activity dramatically increased in the fruit following low-temperature storage indicates stress condition, which results in increase of PPO activity (Mayer, 1987). Josapine cv. depicts consistently higher PPO compared to Morris throughout the storage up to day 28 but no significant differences $(\mathrm{p}<0.05)$ were found for both except at day 14

PPO react by oxidising polyphenols to o-quinones in the presence of oxygen. o-quinones will then polymerise into undesirable brown, red, or black pigments that responsible for tissue browning (Hs 1955). PPO is a key enzyme for enzymatic browning in many fruits which are tightly bound to the chloroplast membrane while phenolic substrates are mainly located in the vacuoles. (Mayer, 1987). However, in cell-damaging treatment, the enzyme may expose to the substrates, leading to the rapid oxidation of phenols (Chazarra et al., 2001). Formation of highly active quinones that react with amino or sulfhydryl groups in proteins or enzymes. These reactions lead to changes in physical, chemical or nutritional characteristics of proteins and, in many cases, to inactivation of enzymes

Plants exhibits a protection mechanism against the effects of ROS by using a complex antioxidant system involving antioxidant compounds such as ascorbate acid and glutathione and antioxidant related enzymes such as superoxide dismutase (SOD), catalase (CAT), ascorbate peroxidase (APX), and peroxidase (POD) (Cao et al., 2011). Sala (1998) previously showed that a positive 
relationship exists between antioxidant enzyme activity and chilling tolerance in harvested fruit. These results suggest that chilling tolerance of harvested fruit could be increased by an enhancing antioxidant enzyme system and reducing peroxidation of membrane lipids.

Ascorbate peroxidase (APX) in higher plants exists in at least three forms: cytosolic, stromal and thylakoid membrane-bound isoforms. Ascorbate peroxidase catalyses the reduction of hydrogen peroxide $\left(\mathrm{H}_{2} \mathrm{O}_{2}\right)$ to water through the preferential oxidation of ascorbate and responds to a wide range of environmental stresses. The expression of APX is related to fruit ripening where it can reduce various organic hydroperoxides such as lipid peroxidase. It has been shown that the enhancement of the active oxygen scavenging system induced by low temperature in potato tubers could result not only in the decrease of ascorbic acids but also in an increment of APX activity that important for protection against the $\mathrm{H}_{2} \mathrm{O}_{2}$ generated during low-temperature storage. In the present study, it was found that chilling-sensitive cv., Morris and chilling-tolerant cv., Josapine showed no significant different $(\mathrm{p}<0.05)$ in APX activity throughout 28 days of suboptimum cold storage, and this finding is in contrary with (Sala, 1998) where APX appears to be more active in chilling-tolerant than in chilling-sensitive cultivars.

Cold stress-induced injury in plants may be related to toxic oxygen (Purvis and Shewfelt, 1993). It was also reported that heat shock can result in oxidative stress, which induces genes involved in the oxidative stress defences (Storozhenko et al., 1998). Catalase is another enzyme that is important in protecting membranes from lipid peroxidation. The previous study by Sala (1998) found the main difference between both CI sensitive and CI tolerant cv. is their ability to break down $\mathrm{H}_{2} \mathrm{O}_{2}$ by CAT activity and co-operation of APX and glutathione reductase activities. A decline in CAT activity during cold stress has been described in different plants by (Ferguson and Dunning, 1986) who found that that there was little effect on $\mathrm{H}_{2} \mathrm{O}_{2}$ levels in the cell cultures with substantial inhibition of CAT activity by 3 -amino-1,2,4triazole due to the participation of other enzymes to keep the peroxide levels down. The findings in the present study are found to be parallel with the previous study by Om-arun and Siriphanich (2005) where catalase activity in Queen before storage is three times higher than that in Smooth Cayenne. After one week of storage, the activity declined considerably.

\section{Conclusion}

This study investigated the changes in the physical quality characteristics and antioxidant related enzyme of two pineapple cv. stored at sub-optimal storage temperature. The development of CI condition significantly affected the EL, TTA, firmness, weight loss, browning index and colour (brightness and redness). Moreover, CI was found to affect activities of PPO, APX and CAT which reflected the oxidative stress occurs due to the development of reactive oxygen species (ROS). In overall based on physical and antioxidant enzyme-related activities, the present study suggested both pineapples cv. would be best sustained in sub-optimal storage temperature $\left(4 \pm 2^{\circ} \mathrm{C}\right)$ up to 14 days.

\section{Conflict of interest}

The authors declare no conflict of interest.

\section{Acknowledgments}

This research was financially supported by Project no. RJ130000.7846.4F726 of Food and Biomaterial Engineering Research Group (FOBERG), University Technology of Malaysia (UTM).

\section{References}

Abdullah, H., Rohaya, M.A. and Engku Hasmah, E.A. (2008). Increasing pineapple fruit resistance to chilling injury during storage by temperature preconditioning. Acta Horticulturae, 768, 217-224. https://doi.org/10.17660/ActaHortic.2008.768.26

Blokhina, O., Virolainen, E. and Fagerstedt, K.V. (2003). Antioxidants, oxidative damage and oxygen deprivation stress, A review. Annals of Botany, 91 (2), 179-194. https://doi.org/10.1093/aob/mcf118

Cao, S., Yang, Z., Cai, Y. and Zheng, Y. (2011). Fatty acid composition and antioxidant system in relation to susceptibility of loquat fruit to chilling injury. Food Chemistry, 127(4), 1777-1783. https:// doi.org/10.1016/j.foodchem.2011.02.059

Chazarra, S., García-Carmona, F. and Cabanes, J. (2010). Evidence for a tetrameric form of iceberg lettuce (Lactuca sativa L.) polyphenol oxidase, purification and characterization. Journal of Agricultural and Food Chemistry, 49, 4870-4875. https://doi.org/10.1021/jf0100301

D’Eeckenbrugge, G. and Leal, F. (2003). Morphology, anatomy and taxonomy. In Bartholomew, D.P., Paull, R.E., Rohrbach, K.G. (Eds). The pineapple, botany, production and uses. p. 13-32. UK: CABI Publishing.

https:// doi.org/10.1079/9780851995038.0013

Ferguson, I.B. and Dunning, S.J. (1986). Effect of 3amino-1,2,4-triazole, a catalase inhibitor, on peroxide content of suspension-cultured pear fruit 
cells. Plant Science, 43(1), 7-11. https:// doi.org/10.1016/0168-9452(86)90100-7

Hassan, A., Othman, Z. and Siriphanich, J. (2011) Pineapple (Ananas comosus L. Merr.). In Yahia, E.A. (Ed) Postharvest biology and technology of tropical and subtropical fruits, p. 194-217. Cambridge, United Kingdom: Woodhead Publishing Limited. https://doi.org/10.1533/9780857092618.194

Hong, K., Xu, H., Wang, J., Zhang, L., Hu, H., Jia, Z., $\mathrm{Gu}, \mathrm{H} ., \mathrm{He}, \mathrm{Q}$. and Gong, D. (2013). Quality changes and internal browning developments of summer pineapple fruit during storage at different temperatures. Scientia Horticulturae, 151, 68-74. https://doi.org/10.1016/j.scienta.2012.12.016

Hossain, M.A. and Rahman, S.M.M. (2011). Total phenolics, flavonoids and antioxidant activity of tropical fruit pineapple. Food Research International, 44(3), 672-676. https:// doi.org/10.1016/j.foodres.2010.11.036

Ibrahim, S.M., Nahar, S., Islam, J.M.M., Islam, M., Hoque, M.M. and Khan, M.A. (2014). Effect of Low Molecular Weight Chitosan Coating on physicochemical Properties and Shelf life Extension of Pineapple (Ananas sativus). Journal of Forest products and industries, 3(3), 161-166.

Lee, S., Choib, H.-K., Choc, S.K. and Kima, Y.-S. (2010). Metabolic analysis of guava (Psidium guajava L.) fruits at different ripening stages using different data- processing approaches. Journal of Chromatography, 878(29), 2983-2988. https:// doi.org/10.1016/j.jchromb.2010.09.003

Lin, D. and Zhao, Y. (2007). Innovation in the Development and Application of Edible Coatings for Fresh and Minimally Processed Fruits and Vegetables. Comprehensive Reviews in Food Science and Food Safety Innovations, 6(3), 60-75. https://doi.org/10.1111/j.1541-4337.2007.00018.x

Lobo, M.G. and Yahia, E. (2016). Biology and postharvest physiology of pineapple. In Lobo, M.G. and Paull, R.E. (Eds). Handbook of Pineapple Technology, Postharvest Science, Processing and Nutrition, p. 39-61. United Kingdom: John Wiley and Sons, Ltd. https:// doi.org/10.1002/9781118967355.ch3

Luengwilai, K., Beckles, D.M., Roessner, U., Dias, D.A., Lui, V. and Siriphanich, J. (2018). Identification of physiological changes and key metabolites coincident with postharvest internal browning of pineapple (Ananas comosus L.) fruit. Postharvest Biology and Technology, 137, 56-65. https:// doi.org/10.1016/j.postharvbio.2017.11.013
Mayer, A.M. (1987). Polyphenol oxidase and peroxidase in plants-Recent progress. Phytochemistry, 26(1), 11 -20. https://doi.org/10.1016/S0031-9422(00)81472-7

Neto, C.G.T., Giacometti, J.A., Job, A.E., Ferreira, F.C., Fonseca, J.L.C. and Pereira, M.R. (2005). Thermal analysis of chitosan-based networks. Carbohydrate Polymers, 62(2), 97-103. https://doi.org/10.1016/ j.carbpol.2005.02.022

Nukuntornprakit, O., Chanjirakul, K., van Doorn, W.G. and Siriphanich, J. (2015). Chilling injury in pineapple fruit, Fatty acid composition and antioxidant metabolism. Postharvest Biology and Technology, 99, 20-26. https://doi.org/10.1016/ j.postharvbio.2014.07.010

Om-arun, N. and Siriphanich, J. (2005). Hydrogen Peroxide and Ascorbic Acid Contents, Superoxide Dismutase and Catalase Activities in Smooth Cayenne and Queen Pineapples During Cold Storage. Acta Horticulturae, 682, 611-616. https:// doi.org/10.17660/ActaHortic.2005.682.78

Paull, R.E. and Chen, C.C. (2003). Postharvest physiology, handling andstorage of pineapple. In Bartholomew, D.P., Paull, R.E. and Rohrbach, K.G. (Eds.). The Pineapple, Botany, Production and Uses. p. 253-279. Wallingford, UK: CABI Publishing. https://doi.org/10.1079/9780851995038.0253

Purvis, A.C. and Shewfelt, R.L. (1993). Does the alternative pathway ameliorate chilling injury in sensitive plant tissues? Physiologia Plantarum, 88 (4), 712-718. https://doi.org/10.1111/j.13993054.1993.tb01393.x

Sala, J.M. (1998). Involvement of oxidative stress in chilling injury in cold-stored mandarin fruits. Postharvest Biology and Technology, 13(3), 255261. https://doi.org/10.1016/S0925-5214(98)00011-8

Shadmani, N., Ahmad, S.H.H., Saari, N., Ding, P. and Tajidin, N.E.E. (2015). Chilling injury incidence and antioxidant enzyme activities of Carica papaya L. "Frangi" as influenced by postharvest hot water treatment and storage temperature. Postharvest Biology and Technology, 99, 114-119. https:// doi.org/10.1016/j.postharvbio.2014.08.004

Shamsudin, R., Daud, W.R.W., Takriff, M.S. and Hassan, O. (2007). Physicochemical Properties of the Josapine Variety of Pineapple Fruit', International Journal of Food Engineering, 3(5), 112. https://doi.org/10.2202/1556-3758.1115

Tehrani, M., Chandran, S., Sharif Hossain, A.B.M. and Nasrulhaq-Boyce, A. (2011). Postharvest physicochemical and mechanical changes in jambu air (Syzygium aqueum Alston) fruits. Australian Journal of Crop Science, 5(1), 32-38. 
Vinson, E.L., Woods, F.M., Kemble, J.M., PerkinsVeazie, P., Davis, A. and Kessler, J.R. (2010) Use of external indicators to predict maturity of miniwatermelon fruit. HortScience, 45(7), 1034-1037. https://doi.org/10.21273/HORTSCI.45.7.1034

Youryon, P., Supapvanich, S., Kongtrakool, P. and Wongs-Aree, C. (2018). Calcium chloride and calcium gluconate peduncle infiltrations alleviate the internal browning of Queen pineapple in refrigerated storage. Horticulture, Environment, and Biotechnology, 59(2), 205-213. https:// doi.org/10.1007/s13580-018-0028-9

Youryon, P., Wongs-Aree, C., McGlasson, W.B., Glahan, S. and Kanlayanarat, S. (2013). Alleviation of internal browning in pineapple fruit by peduncle infiltration with solutions of calcium chloride or strontium chloride under mild chilling storage. International Food Research Journal, 20(1), 239246.

Zaulia, O. and Suhaila, M. (2007). Effect of various coatings on the chemical changes of different pineapple cultivars (N36 and Gandul) at low temperature storage. Journal of Tropical Agriculture and Food Science, 35(1), 107-120.

Zhang, X. and Shao, X. (2015). Characterisation of polyphenol oxidase and peroxidase and the role in browning of loquat fruit', Czech Journal of Food Sciences, 33(2), 109-117. https:// doi.org/10.17221/384/2014-CJFS

Zhou, Y., Dahler, J.M., Underhill, S.J.R. and Wills, R.B.H. (2003). Enzymes associated with blackheart development in pineapple fruit'. Food Chemistry, 80 (4), 565-572. https://doi.org/10.1016/S0308-8146 (02)00375-8 